\title{
1 Analisis Strategi Bertahan Hidup di Tengah Isu Ketersediaan Sumber Daya Alam \\ (Studi Perbandingan Masyarakat Adat La Pedrera (Kolombia) dan Masyarakat Desa Tanjung Labu (Indonesia)
}

Widya Handini

widyahandini@stisipolp12.ac.id

STISIPOL Pahlawan 12

\begin{abstract}
ABSTRAK
Kerawanan pangan dipahami sebagai "kurangnya akses yang terjamin terhadap kecukupan dari makanan yang aman dan bergizi untuk pertumbuhan normal dan hidup sehat.” Terlepas dari kekayaan alam yang ada, masyarakat adat La Pedrera, Amazonas terancam oleh perubahan lingkungan yang menyebabkan adanya kerawanan pangan dalam populasi mereka. Hal yang sama terjadi pada masyarakat Desa Tanjung Labu. Mengambil pendekatan studi kasus, penelitian ini membahas tentang pertanyaan penelitian berikut: bagaimana rumah tangga di La Pedrera dan masyarakat Desa Tanjung Labu mengatasi rawan pangan? Data sekunder dari survei kuesioner terhadap 159 rumah tangga di La Pedrera dianalisis. Data primer dari 30 rumah tangga di Desa Tanjung Labu juga dianalisis. Studi ini menemukan bahwa masyarakat La Pedrera menggunakan 14 strategi penanggulangan yang berbeda untuk mengatasi kekurangan sumber daya alam terkait sumber daya alam, khususnya kebutuhan pangan. Adapun masyarakat Desa Tanjung Labu menggunakan 12 strategi dengan persentase yang berbeda. Studi ini menyimpulkan strategi antara masyarakat La Pedrera dan masyarakat Tanjung Labu memiliki perbedaan sesuai dengan situasi kultural masyarakat dan kondisi geografis yang ada. Hasil studi ini diharapkan dapat menjadi bahan acuan dalam pengambilan kebijakan terkait kerawanan pangan di kedua tempat.
\end{abstract}

Kata Kunci : Kerawanan Pangan; masyarakat adat; La Pedrera; Tanjung Labu

\section{ABSTRACT}

Food insecurity is understood as "lack of secure access to sufficient, safe and nutritious food for normal growth and healthy living." Despite the existing of natural wealth, the indigenous people of La Pedrera, Amazonas are threatened by environmental changes that cause food insecurity in their population. The same thing happened to the people of Tanjung Labu Village. Taking a case study approach, this study addresses the following research questions: how do households in La Pedrera and the people of Tanjung Labu Village cope with food insecurity? Secondary data from a questionnaire survey of 159 households in La Pedrera were analyzed. Primary data from 30 households in Tanjung Labu Village were also analyzed. This study found that the people of La Pedrera used 14 different coping strategies to overcome the shortage of natural resources related to natural resources, especially food needs. The people of Tanjung Labu Village use 12 strategies with different percentages. This study concludes that the strategy between the La Pedrera community and the Tanjung Labu community has differences according to the cultural situation of the community and the existing geographical conditions. The results of this study are expected to be used as a reference in making policies related to food insecurity in both places.

Keywords: Food Insecurity; Indigenous People; La Pedrera; Tanjung Labu 


\section{PENDAHULUAN}

Pembanguna Kerawanan pangan dipahami sebagai "kurangnya akses yang aman terhadap makanan aman dan bergizi yang memadai untuk pertumbuhan normal dan kehidupan sehat" (FAO, 2014). Malnutrisi serta kelaparan ekstrem menjadi hambatan pembangunan, dengan mayoritas orang yang terkena kelaparan di negara berkembang serta daerah perdesaan. Ada sekitar 795 juta orang yang terdeteksi kekurangan gizi kronis pada tahun 2014 karena konsekuensi degradasi lingkungan. Oleh karena itu, Tujuan Pembangunan Berkelanjutan (SDG) bertujuan untuk memberantas kelaparan dan malnutrisi pada tahun 2030, dan memastikan semua orang-khususnya anak-anakmemiliki akses terhadap makanan bergizi (UNDP, 2016).

Meskipun dianugerahi kekayaan alam yang melimpah, masyarakat adat Amazon terancam oleh perubahan lingkungan yang menyebabkan adanya kerawanan pangan pada populasi mereka (Ortiz et al., 2013). Sekitar sepertiga dari populasi di Amazon dikategorikan sebagai tempat yang tidak aman dalam aspek makanan (UNEP et al., 2009). Di banyak kota di Brazil, kemiskinan dan tingkat kematian bayi berada di atas rata-rata nasional (IBGE, 2010). Pada tahun 2009, Survei Nasional Masyarakat Adat untuk Kesehatan Masyarakat dan Gizi Primer memperkirakan prevalensi kekerdilan sebesar 40,8\% (tinggi badan rendah untuk usia sebagai indikator kurang gizi yang kronis) di antara anak-anak di bawah usia lima tahun di wilayah utara (Amazon), atau di atas lima kali rata-rata nasional (7,1\%) (Horta et al., 2013). Salick dan Byg (2007) menjelaskan bahwa situasi makanan, gizi, dan kesehatan masyarakat di Amazon Kolombia belum ditangani secara komprehensif. Selain itu, hanya ada sedikit informasi yang dipublikasikan mengenai penyebab kerawanan pangan di Amazon, terutama di kalangan masyarakat adat. Sayangnya, penelitian mengenai layanan ekosistem dalam kaitannya dengan pengentasan kemiskinan (termasuk ketahanan pangan) di Amerika Latin masih sangat terbatas (Suich, 2015). Tak cuma itu, data untuk produksi pertanian dan ketahanan pangan di Lembah Amazon sangat buruk serta ketinggalan zaman (Ortiz et al., 2013).

Desa Tanjung Labu adalah salah satu desa terpencil di Kecamatan Lepar Pongok, Kabupaten Bangka Selatan, Provinsi Bangka Belitung, Indonesia. Kecamatan ini memiliki empat desa, yaitu Desa Tanjung Labu, Desa Tanjung Sangkar, Desa Kumbung, dan Desa Penutuk. Ibu kota Kecamatan Lepar Pongok terletak di Desa Tanjung Labu. Secara geografis, wilayah Kecamatan Lepar Pongok dikelilingi laut yang sebagian besar masyarakat bergantung pada hasil melaut. Selain melaut, masyarakat Tanjung Labu juga bertambang timah dan bertani lada.

Ada beberapa permasalahan lingkungan yang dihadapi oleh masyarakat Tanjung Labu. Pertama, maraknya tambang timah yang berdampak negatif terhadap lingkungan. Kedua, adanya perluasan kawasan perkebunan kelapa sawit yang mengurangi area hutan sekaligus memperkecil kesempatan masyarakat menikmati hasil hutan yang ada; belum lagi dampak negatif berupa hilangnya resapan air dari perluasan perkebunan kelapa sawit. Masalahmasalah ini sedikit banyak berdampak terhadap kesediaan bahan makanan, sumber daya alam, ataupun pundi-pundi ekonomi yang dapat dimanfaatkan masyarakat. 
Menghadapi situasi kekurangan makanan, setiap orang mempunyai strategi yang berbeda-beda, misalnya mengubah pilihan makanan. Strategi bertahan hidup atau coping strategy (CS) didefinisikan oleh Snell dan Staring (2001) sebagai perilaku yang dipilih oleh individu dan rumah tangga di dalam kelompok sosial ekonomi yang buruk untuk membatasi pengeluaran mereka. Strategi bertahan hidup ini sebelumnya telah digunakan sebagai indikator ketahanan pangan rumah tangga oleh berbagai peneliti (Christiansen dan Boisvert, 2000). Beberapa strategi tingkat rumah tangga untuk mengatasi kerawanan pangan telah diidentifikasi, termasuk perubahan pola makan jangka pendek seperti dengan mengurangi konsumsi, mengubah konsumsi rumah tangga, meningkatkan kebergantungan pada makanan liar, transformasi pola produksi tanaman dan ternak, serta penjualan aset (Corbett, 1988). Seperti yang ditunjukkan oleh Kuhnlein dan Receveur (1996), variasi dalam hubungan antara ekonomi dan diet didasarkan pada kondisi lokal (termasuk lokasi geografis), sifat perubahan ekonomi, dan kepercayaan budaya.

Studi ini bertujuan untuk meneliti serta membandingkan strategi yang dilakukan oleh masyarakat adat La Pedrera di Amazon dan masyarakat Desa Tanjung Labu dalam menanggulangi kondisi kekurangan bahan makanan atau kekurangan sumber daya alam di kehidupan sehari-hari. Kedua masyarakat ini memiliki kesamaan sebagai salah satu wilayah terpencil dengan karakteristik khas di negara masingmasing. Secara khusus, pemahaman tentang hal ini diperlukan untuk memahami situasi masyarakat. Hal ini bermanfaat dalam pengelolaan kebijakan, yakni terkait strategi efektif yang dapat diterapkan dalam memastikan tingkat ketahanan pangan yang lebih baik.

\section{METODOLOGI}

\section{Sumber Data dan Lokasi Studi}

Penelitian ini didasarkan pada data sekunder dan data primer. Data pertama terkait masyarakat La Pedrera dikumpulkan oleh ASSETS Project (http://espa-assets.org/) selama September 2013 di La Pedrera, Amazon, Kolombia. Amazon Kolombia mencakup area sekitar $400.000 \mathrm{~km}^{2}$ di bagian utara-barat Lembah Amazon dengan keragaman alam dan budaya yang tinggi. Wilayah ini terdiri dari 52 kelompok etnis dari 13 saham linguistik dan 10 bahasa terisolasi (Kronik dan Verner, 2010). La Pedrera adalah sebuah kota dan kota madya di bagian selatan Kolombia. Secara administratif, wilayah La Pedrera terbagi menjadi empat cagar alam; dua wilayah asli yang tidak resmi dan dua cadangan hutan negara (Gambar 1). Data dikumpulkan melalui survei rumah tangga dari 159 rumah tangga dari 11 komunitas (sebuah sensus penuh). Proyek ASSETS juga melakukan diskusi kelompok terarah tentang ketahanan pangan di masyarakat (RamirezGomez et al., 2015; Schreckenberg et al., 2016). 


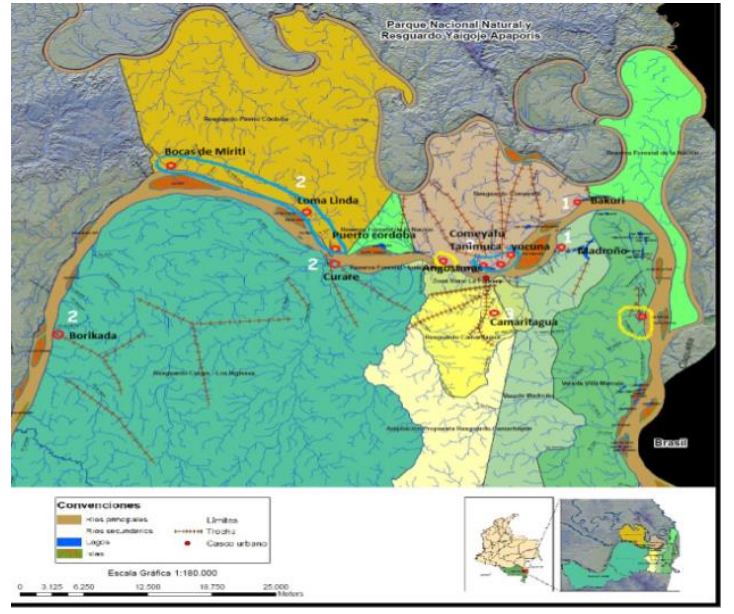

Gambar 1. Peta Kawasan La Pedrera. (sumber: ASSETS Project, 2015)

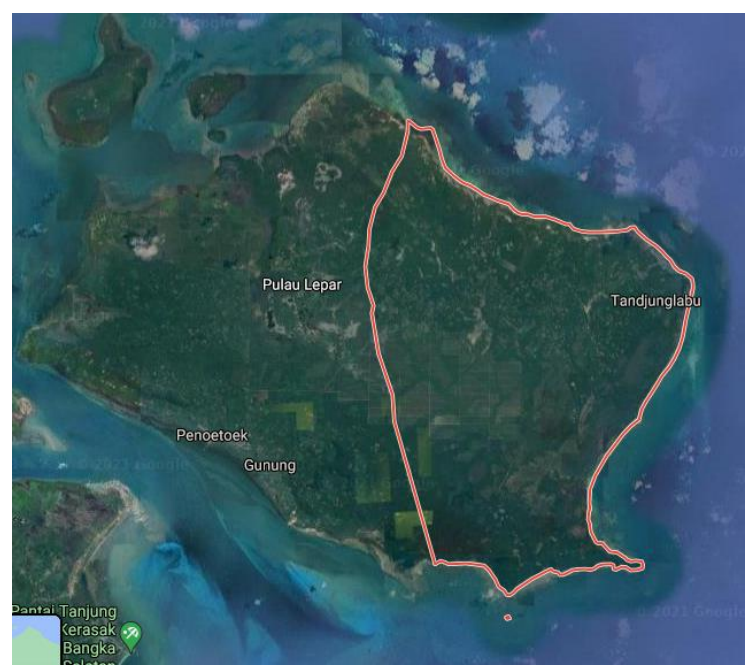

Gambar 2. Peta Desa Tanjung Labu (sumber: Google Maps, 2021)

Pengambilan data di Desa Tanjung Labu menggunakan data primer melalui kuesioner yang dilakukan oleh peneliti dengan 30 sampel pada tahun 2021. Peneliti memberikan kuesioner yang berisikan pertanyaan yang sama dengan pertanyaan kuesioner pada masyarakat $\mathrm{La}$ Pedrera terkait dengan strategi bertahan hidup ketika kesulitan makanan. Desa Tanjung Labu merupakan salah satu desa yang terpencil di Indonesia, terletak di Kecamatan Lepar Pongok, Kabupaten Bangka Selatan.

\section{Identifikasi Strategi Bertahan Hidup dari Masyarakat yang Mengalami Kerawanan Pangan}

Strategi bertahan hidup masyarakat $\mathrm{La}$ Pedrera diperoleh dengan mendatangi rumah masyarakat serta melakukan wawancara. Hasil pengambilan data kemudian digabungkan dan dibuat satu kesimpulan terhadap strategi umum yang dilakukan. Pengambilan data lokasi sumber daya alam dilakukan oleh tim ASSETS Project bersamaan dengan wawancara masyarakat adat di La Pedrera.

Strategi bertahan hidup masyarakat Tanjung Labu diperoleh dengan mendatangi rumah masyarakat. Peneliti memberikan kuesioner berisi pertanyaan terkait strategi bertahan hidup masyarakat Tanjung Labu. 


\section{HASIL DAN PEMBAHASAN}

\section{Strategi Menghadapi Kerawanan Pangan di La Pedrera}

Ada 14 strategi penanggulangan yang digunakan oleh rumah tangga di La Pedrera yang telah melaporkan mengalami keresahan pangan (Tabel 1). Strategi yang paling sering digunakan adalah melakukan kegiatan pengumpulan makanan (termasuk berburu, memancing, mengumpulkan makanan liar) di daerah yang sebelumnya tidak dikunjungi, dan membatasi ukuran porsi pada waktu makan (masing-masing 18,1\%). Strategi berikutnya yang paling sering digunakan adalah meminjam makanan dari teman atau saudara $(17,6 \%)$, diikuti dengan mengurangi jumlah makanan yang dimakan setiap hari $(16,2 \%)$. Strategi coping yang paling sering digunakan adalah pertukaran pekerjaan untuk makanan, memberi makan anggota rumah tangga yang bekerja dengan mengorbankan anggota nonpekerja, dan mengonsumsi persediaan benih yang diadakan untuk musim depan (masing-masing dengan $0,5 \%)$.

\begin{tabular}{|l|r|}
\hline \multicolumn{1}{|c|}{ Behaviour } & (\%) \\
\hline $\begin{array}{l}\text { Limit portion size at } \\
\text { mealtimes }\end{array}$ & 18.1 \\
\hline $\begin{array}{l}\text { Conduct food gathering } \\
\text { activities for longer or travel } \\
\text { to areas not visited before }\end{array}$ & 18.1 \\
\hline $\begin{array}{l}\text { Borrow food from a friend or } \\
\text { relative }\end{array}$ & 17.6 \\
\hline $\begin{array}{l}\text { Reduce the number of meals } \\
\text { eaten in a day }\end{array}$ & 16.2 \\
\hline Purchase food on credit & 7.1 \\
\hline $\begin{array}{l}\text { Rely on less preferred and } \\
\text { less expensive foods }\end{array}$ & 5.6 \\
\hline $\begin{array}{l}\text { Restrict consumption by } \\
\text { adults in order for small } \\
\text { children to eat }\end{array}$ & 2.4 \\
\hline $\begin{array}{l}\text { Send women and/or children } \\
\text { to conduct foraging activities }\end{array}$ \\
\hline $\begin{array}{l}\text { Send household members to } \\
\text { eat somewhere else }\end{array}$ \\
\hline $\begin{array}{l}\text { Borrow money from friends } \\
\text { or relatives to purchase food }\end{array}$ \\
\hline
\end{tabular}




\begin{tabular}{|l|r|}
\hline \multicolumn{1}{|c|}{$\begin{array}{l}\text { Makeup recipes with } \\
\text { forest products }\end{array}$} & 1 \\
\hline $\begin{array}{l}\text { Consume seed stock held for } \\
\text { next season }\end{array}$ & 0.5 \\
\hline $\begin{array}{l}\text { Feed working members at the } \\
\text { expense of non-working } \\
\text { members }\end{array}$ & 0.5 \\
\hline Work in exchange for food & 0.5 \\
\hline Total & 100 \\
\hline
\end{tabular}

Tabel 1. Strategi yang digunakan masyarakat La Pedrera

\section{PRESENTASE STRATEG I BERTAHAN HIDUP MASYARAKAT}

\section{LA PEDRERA}

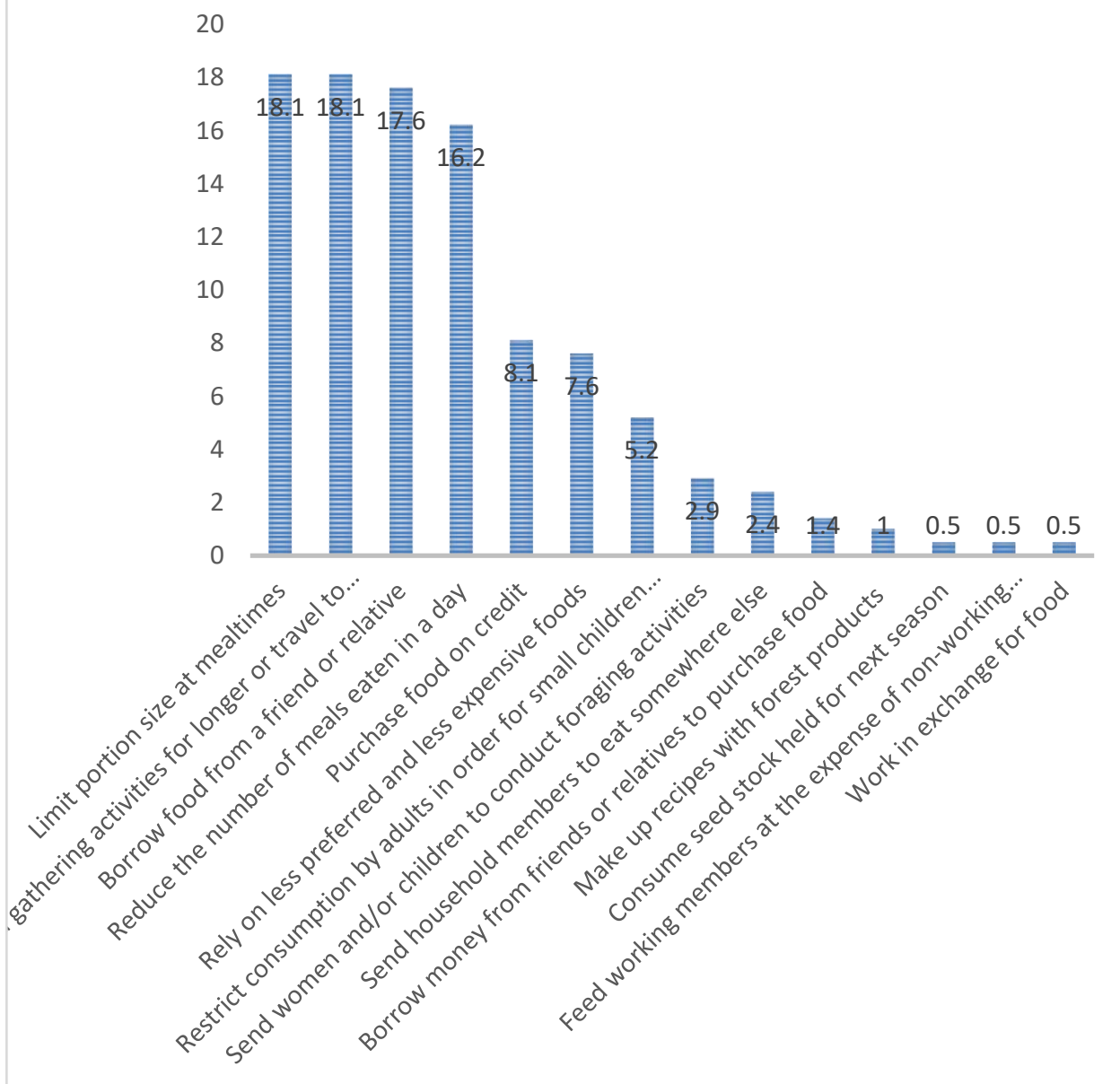




\section{Grafik 1. Persentase Strategi Bertahan Hidup Masyarakat La Pedrera}

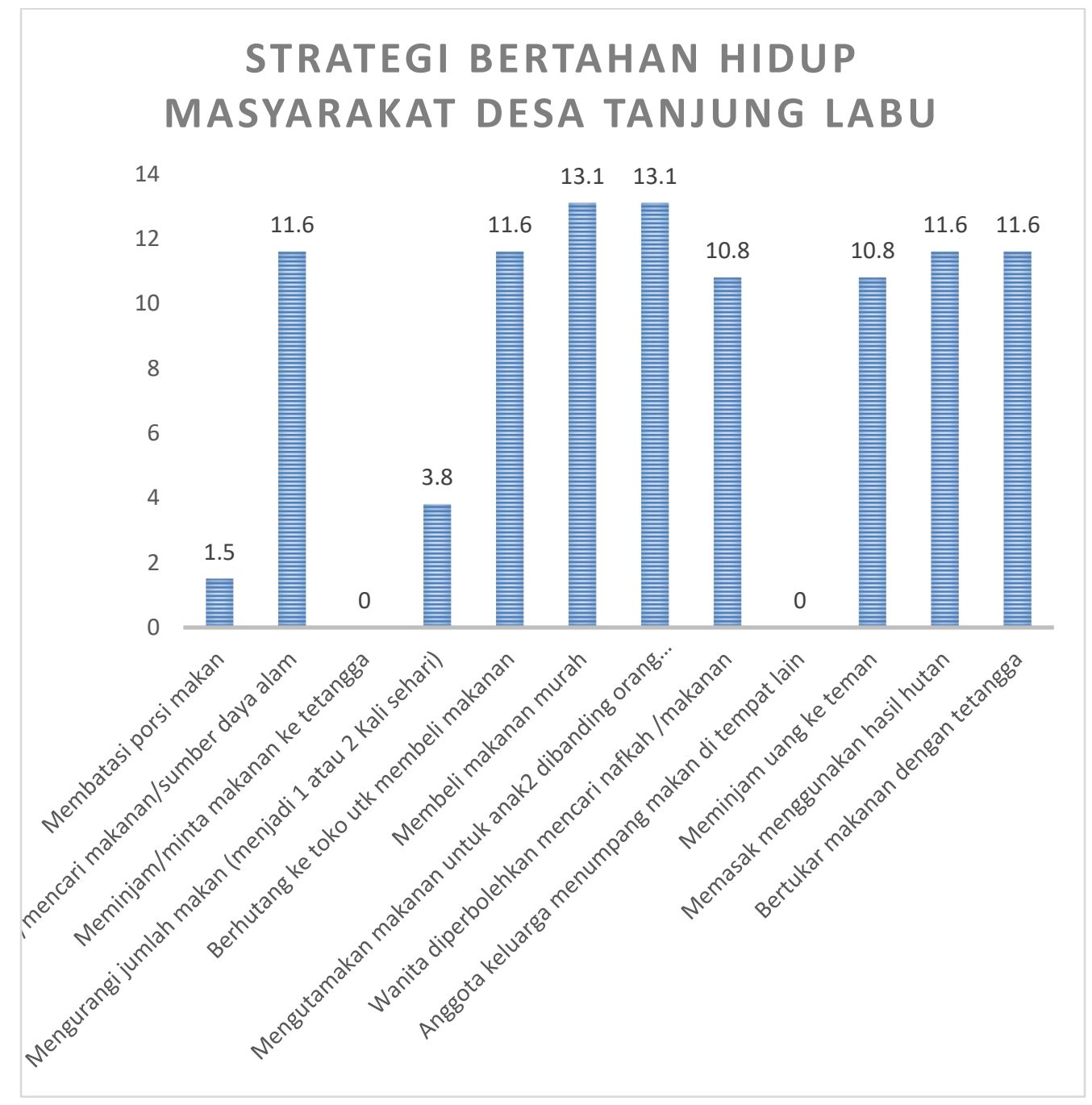

\section{Grafik 2. Persentase Strategi Bertahan Hidup Masyarakat Desa Tanjung Labu}

Masyarakat desa Tanjung Labu memiliki tren yang berbeda dengan masyarakat La Pedrera. Di antaranya ada beberapa strategi yang memiliki persentase tinggi di masyarakat La Pedrera tapi di masyarakat Tanjung Labu justru memiliki persentase strategi yang rendah; demikian pula sebaliknya.

Masyarakat Tanjung Labu memiliki persentase tertinggi dalam dua strategi, yakni membeli makanan yang lebih murah $(13,1 \%)$, serta mengutamakan makanan untuk anggota keluarga yang lebih muda $(13,1 \%)$. Persentase tertinggi kedua adalah lebih lama bekerja, berutang ke toko, memasak menggunakan hasil hutan, serta bertukar makanan dengan tetangga (masing-masing 11,6\%). Posisi ketiga ditempati oleh strategi memperbolehkan atau meminta wanita untuk bekerja dan meminjam uang ke teman $(10,8 \%)$. 
Di posisi terendah ditempati oleh strategi meminjam atau meminta makanan ke tetangga dan menumpang makan di tempat lain (0\%). Posisi terendah kedua ditempati oleh strategi mengurangi jumlah makan (3,8\%), dan posisi terendah ketiga adalah strategi membatasi porsi makan (1,5\%).

\section{DISKUSI}

Agar dianggap aman, anggota rumah tangga harus dapat menemukan dan mendapatkan makanan tanpa kesulitan, mencuri, atau strategi penanganan lainnya (Anderson, 1990). Indikator ketersediaan makanan rumahan adalah estimator tidak langsung terhadap kerawanan pangan individu atau rumah tangga (Correa, 2007). Selain itu, kerawanan pangan bukan hanya masalah ketersediaan pangan (per kapita), yang bergantung pada persediaan makanan dan produksi, tapi juga bergantung pada akses masyarakat terhadap makanan dan kemampuan mereka untuk memanfaatkannya (Buchi dan Muro, 2016). Persepsi orang-orang di setiap rumah tangga dalam hal apa yang "cukup" atau "tidak cukup" mungkin berbeda, terutama di seluruh rumah tangga di lokasi yang berbeda, seperti daerah semi perkotaan dan daerah di dekat hutan yang menunjukkan kecenderungan menurunnya laporan.

Mengenai perilaku penanggulangan, strategi yang digunakan oleh masyarakat adat di La Pedrera kemungkinan hasil dari gaya hidup mereka dalam hal kondisi sosial, ekonomi, dan ekosistem mereka karena mereka hidup sebagai penduduk asli di daerah perdesaan dan berhutan. Strategi bertahan hidup yang paling sering digunakan adalah melakukan kegiatan pengumpulan makanan di daerah yang sebelumnya tidak dikunjungi, dan membatasi ukuran porsi pada waktu makan. Untuk itu pemerintah perlu memastikan bahwa masyarakat memiliki wilayah yang "jauh lebih jauh" untuk dikunjungi guna mendapatkan makanan karena masyarakat adat perlu memiliki kendali atas wilayah lahan yang luas dan tidak terancam oleh imigrasi ataupun kehilangan lahan akibat konsesi lahan.

Sebaliknya, masyarakat Desa Tanjung Labu bahkan tidak memberikan atau memilih opsi tersebut dalam hal mencari makanan ke tempat yang belum pernah dikunjungi sebelumnya. Membatasi makanan menjadi opsi dengan persentase terendah kedua. Hal ini terlihat sangat kontras sekali di antara kedua tipe masyarakat. Hal ini kemungkinan dikarenakan daerah Tanjung Labu memiliki area yang tidak seluas La Pedrera sehingga opsi pertama tidaklah berlaku pada masyarakat Tanjung Labu. Terkait dengan pembatasan porsi makanan, bagi masyarakat Tanjung Labu hal ini dimungkinkan terkait dengan gaya hidup yang telah mengakar.

Dalam hal meminjam makanan dari teman atau kerabat, berdasarkan DFID (1999), interaksi sosial antara keluarga dan teman membuat kontribusi penting bagi keamanan rumah tangga. Di masyarakat La Pedrera, strategi meminjam makanan ke tetangga menempati posisi tertinggi kedua. Namun, di Desa Tanjung Labu, meminta/meminjam makanan ke tetangga menempati urutan terakhir. Perbedaan ini menjadi indikasi dua hal; pertama, tingginya sikap gengsi masyarakat Tanjung Labu untuk meminta ataupun 
meminjam makanan; kedua, persepsi bahwa meminjam makanan itu menggambarkan cukup parahnya kondisi perekonomian keluarga.

Terkait dengan menugaskan wanita untuk mencari makanan/sumber daya alam/uang, masyarakat La Pedrera memiliki persentase yang cenderung kecil. Hal ini dikarenakan diet lokal di La Pedrera sangat bergantung pada penangkapan ikan dan perburuan yang merupakan tugas lakilaki (ASSETS Project, 2015). Adapun di masyarakat Tanjung Labu, persentase penugasan wanita memiliki nilai yang cukup tinggi. Hal ini menunjukkan ada perbedaan orientasi gender dalam penugasan pencarian makanan di antara masyarakat kedua daerah.

Hal kontras lainnya adalah terkait strategi bertukar makanan ke tetangga, memasak menggunakan hasil hutan, dan meminjam uang ke

\section{KESIMPULAN}

Strategi tertentu yang dipilih oleh rumah tangga dapat diharapkan bervariasi sesuai dengan mata pencaharian masing-masing. Ada 14 strategi penanggulangan yang berbeda yang digunakan oleh masyarakat adat La Pedrera. Hasil yang diperoleh menunjukkan bahwa ada variasi dalam tanggapan terhadap ketersediaan makanan di antara populasi manusia. Adapun di Tanjung Labu masyarakat menggunakan 12 strategi (mengikuti 12 strategi yang sama dengan masyarakat La Pedrera). Namun, ada beberapa perbedaan yang sangat signifikan terkait persentase strategi yang digunakan di antara dua masyarakat. Hal ini dimungkinkan oleh perbedaan budaya dan lingkungan antara masyarakat La Pedrera dan Tanjung Labu. teman. Di Desa Tanjung Labu, strategi ini menempati persentase yang termasuk tinggi, namun sangat kontras dengan persentase di masyarakat La Pedrera. Perbedaan ini dimungkinkan karena interaksi sosial terkait meminjam uang. Meminjam uang merupakan aktivitas yang cukup biasa di Tanjung Labu, namun tidak demikian untuk masyarakat di $\mathrm{La}$ Pedrera. Hal yang sama berlaku dalam bertukar makanan kepada tetangga. Akan tetapi, hal yang cukup unik terjadi pada strategi memasak menggunakan hasil hutan. Didapati persentase yang tinggi di Tanjung Labu, namun sangat rendah di La Pedrera. Padahal, luas hutan La Pedrera lebih besar dibandingkan Tanjung Labu. Perbedaan ini kemungkinan dikarenakan oleh kebiasaan masyarakat terkait pengelolaan hasil hutan.

Penelitian lebih lanjut dianjurkan untuk memeriksa hubungan antara strategi masyarakat dengan strategi yang dilakukan oleh pemerintah setempat untuk memastikan bahwa kebijakan yang dilakukan sesuai dengan situasi dan kondisi lokal yang ada. Selain itu, pemerintah harus merekomendasikan strategi tertentu untuk membantu masyarakat adat bertahan menghadapi ancaman kerawanan pangan, semisal: memastikan bahwa penduduk asli memiliki wilayah untuk mendapatkan makanan di lingkungan mereka; (2) memastikan perekonomian masyarakat dapat meningkat; (3) meningkatkan keterampilan dasar masyarakat untuk meningkatkan produktivitas mereka dalam mendapatkan makanan. 


\section{REFERENSI}

Anderson, S. A. (1990). "Core Indicators of Nutritional State for Difficult-to-Sample Populations." The Journal of Nutrition, 120(11), 1557-1599

Burchi, F., \& De Muro, P. (2016). "From Food Availability to Nutritional Capabilities: Advancing Food Security Analysis." Food Policy, 60, 10-19

Christiaensen, L. J., \& Boisvert, R. N. (2000). On Measuring Household Food Vulnerability: Case Evidence from Northern Mali. Department of Agricultural, Resource, and Managerial Economics, Cornell University

Corbett, J. (1988). "Famine and Household Coping Strategies." World Development, 16(9), 1099-1112

Corrêa, A. M. S. (2007). "Food Insecurity as Measured by Individual Perceptions." Estudos Avançados, 21(60), 143-154

DFID, U. K. (1999). Sustainable Livelihoods Guidance Sheets. London: DFID.

FAO. (2014). FAOSTAT Statistical Database. Food and Agriculture Organization of The United Nations, Rome. http://faostat.fao.org/ Garcia, G. S., Willcock, S., ...\& Poppy, G. M. (2015). "Analysis of Ecosystem Services Provision in the Colombian Amazon Using Participatory Research and Mapping Techniques." Ecosystem Services, 13, 93107

Horta, B. L., Santos, R. V., Welch, J. R., Cardoso, A. M., dos Santos, J. V., Assis, A. M. O., ... \& Coimbra Jr, C. E. (2013).
"Nutritional Status of Indigenous Children: Findings from the First National Survey of Indigenous People's Health and Nutrition in Brazil." International Journal for Equity in Health, 12(1), 1

IBGE. (2010). Indicadores Sociais Municipais,

Brazilian Demographic Census 2010 Retrieved August 25, 2016, https://biblioteca.ibge.gov.br/index.php/biblio teca-catalogo view $=$ detalhes $\&$ id $=249230$

Kronik, J., \& Verner, D. (2010). Indigenous Peoples and Climate Change in Latin America and the Caribbean. World Bank Publications

Kuhnlein, H. V., \& Receveur, O. (1996). "Dietary Change and Traditional Food Systems of Indigenous Peoples." Annual Review of Nutrition, 16(1), 417-442

Ortiz, R., Nowak, A., Lavado, A., \& Parker, L. (2013). "Food Security in Amazonia." Report for Global Canopy Programme and International Center for Tropical Agriculture as part of the Amazonia Security Agenda Project

Ramirez-Gomez, S. O., Torres-Vitolas, C. A., Schreckenberg, K., Honzák, M., Cruz-

Salick, J., \& Byg, A. (Eds.). (2007). Indigenous Peoples and Climate Change. Oxford: Tyndall Centre for Climate Change Research Schreckenberg, K., Torres Vitolas, C.A., Willcock, S., Shackleton, C., Harvey, C.A. and Kafumbata, D. (2016). "Participatory Data Collection for Ecosystem Services Research: A Practitioner's Manual." ESPA Working Paper Number 3. Available at: http://www.espa.ac.uk/files/espa/PRA-

Manual.pdf 
Snel, E., \& Staring, R. (2001). "Poverty,

Migration, and Coping Strategies: An

Introduction." Focal European Journal of

Anthropology, 38, 7-22

Suich, H., Howe, C., \& Mace, G. (2015).

"Ecosystem Services and Poverty

Alleviation: A Review of the Empirical

Links." Ecosystem Services, 12, 137-147

UNDP Sustainable Development Goals. (2016,

August 28).

http://www.undp.org/content/undp/en/home/

sustainable-development-goals/goal-2-zero-

hunger.html

United Nations Department of Economic. (2009). State of the World's Indigenous Peoples

(Vol. 9). United Nations Publications

Zeballos, H. et al.(2011) Seguridad Alimentaria en Bolivia. Coloquios Económicos, 22 
